\title{
http://bjas.journals.ekb.eg \\ Doppler and Ultrasound Assessment of Placental Implantation Abnormalities in Post Caesarean \\ H.M.Farouk ${ }^{1}$, M.R.Fayed ${ }^{2}$ and N.A.Arabi ${ }^{1}$ \\ ${ }^{1}$ Radio-Diagnosis Dept., Faculty of Medicine, Benha Univ., Benha, Egypt \\ ${ }^{2}$ Obstetrics and Gynacology Dept., Faculty of Medicine, Benha Univ., Benha, Egypt \\ E-Mail:Nahla@gmail.com
}

Abstract

Placenta accreta has now become an important aetiology of maternal morbidity and mortality. The condition is defined as abnormal adherence of the placenta to the uterus.useColour Doppler and ultrasound for assessment of placental implantation abnormalities in post caesarean females. The examine including 50 female patients with agdistis went starting with 19 will 40 a considerable length of time 0ld (mean agdistis 55 \pm 10 . 28) who need a sonographic criteria of placenta Previa, all ladies were subjected with finish history taking, guiding and assent starting with those lady Furthermore her husband, Grey-scale Furthermore shade doppler ultrasonography might have been performed. Around the 50 patients with placenta previa, 40 patients indicated follower placenta, 30 patients with placenta accreta, 2 patients for placenta increta and the keep going 8 patients indicated placenta percreta for bladder intrusion. The 8 patients for placenta percreta indicated bladder Attack Furthermore needed grade bladder repair shed Throughout the operation. Those conclusive analysis for placenta previa without accreta might have been settled on clinched alongside 10 out of the 50 patients. Greyscale ultrasonography need $77.8 \%$ affectability emulated by force doppler for $66.7 \%$ affectability. Both gray scale Also color doppler ultrasonography were exceptionally imperative to diagnosing placenta accreta prenatal to decrease maternal fetal mortal sin Furthermore horribleness Anyway shade doppler may be higher affectability and specificity.

Keywords: Doppler, Ultrasound, Placental implantation, Post caesarean.

\section{Introduction}

Faulty placental emplacement need been connected with a range from claiming difficulties about pregnancy including preeclampsia, intrauterine development restriction, What's more preterm labour, preterm premature break from claiming membranes, late spontaneous abortion, Also abruption placentae [1].

Symptomatic ultrasonography need been Previously, clinical obstetrics for near half-acentury. However, in the literature, examination of the placenta shows up on make treated with lesquerella consideration over the embryo or those pregnant uterus. This may be to a degree unexpected, provided for those clear significant capacities this organ performs Throughout those whole pregnancy. Examination of the placenta assumes An first part over appraisal of typical and abnormal pregnancies [2].

An deliberate sonographic assessment of the placenta ought further bolstering lnclude : location, visual estimation of the size (and ,if showing up abnormal, estimation from claiming thickness or volume) ,implantation, morphology, anatomy,as great as An quest for anomalies for example, extra lobes and tumors. Extra appraisal for different gestations comprise from claiming looking at the interceding membranes (if present). The current Audit acknowledges the Different placental characteristics, Likewise they camwood make assessed Eventually Tom's perusing ultrasound, and the clinical hugeness of abnormalities from claiming these Characteristics. Various What's more differed pathologies of the placenta could a chance to be distinguished Toward schedule ultrasonography. It may be officeholder on the clinician performing obstetrical ultrasonography should inspect those placenta On points Furthermore clinched alongside a deliberate design due to the sweeping clinical hugeness and conceivably avoidable separate outcomes for large portions about these abnormalities [2]. Placenta accreta is a state of abnormal placental implantation On which those placental tissue attacks past the decidua basalis, it might attack under alternately Significantly through those myometrium and contiguous organs. For example, the urinary bladder, the frequency need been climbing for later quite some time. Its a standout amongst those essential obstetric difficulties [3].

Nowadays, prompting noteworthy maternal horribleness and mortal sin. On previous this state might have been frequently all the diagnosed toward those the long haul about conveyance At enormous Furthermore unforeseen discharge happened. Hysterectomy, connected with noteworthy physical What's more mental consequences, might have been normally the just administration choice. Concerning illustration a greater amount obstetricians need get mindful from claiming this condition, early ID number with antenatal imaging symptomatic engineering organization 
need get conceivable. Ultrasonography examine assumes a paramount part in the antenatal finding. Different sonographic offers for different specificity Also affectability bring been depicted in the written works. For such information, more exact guiding camwood a chance to be advertised of the moms and their groups in the recent past conveyance. This conveyance might Additionally make orchestrated In An positive position occasion when in an organization the place multidisciplinary help may be available, emergency unit physician, urology surgeon, or other master would alluring. Separated starting with hysterectomy, Different types of preservationist administration might Additionally make recognized At those finding may be committed former with conveyance. Fruitfulness camwood accordingly a chance to be safeguarded [3].

This study meant to utilize shade doppler and ultrasonography to evaluation of placental implantation abnormalities to post cesarean females.

\section{Patients and methods}

The study including 50 female patients with age ranged from 19 to 40 years 0ld (mean age $55 \pm 10.28$ ) who has a sonographic criteria of placenta Previa and underwent previous LSCS referred from the gynecological clinic to the Radiology department.

The study was conducted in the Banha university hospital .Dr/Hisham Farouk radiology center \&Banha Insurance Hospital during a period from January 2019 to September 2019.

\section{Inclusion criteria}

1- Gestational age more than 27 weeks as determined by first day of last menstrual period and confirmed by ultrasound.

2- Placenta previa anterior major or minor degree as confirmed by ultrasound. The diagnosis of major previa was based on the presence of placental tissue covering the internal cervical os. Minor previa was diagnosed when the placenta was within 2 $\mathrm{cm}$ from the internal cervical os but did not cover it.

3- Clinically stable that do not require immediate interference .

4- Agreed to participate in the study.

\section{Exclusion criteria} scar.

Pregnant women without previous uterine

All women were subjected tocomplete history taking, Counseling and consent from the woman and her husband, Grey-scale and color Doppler ultrasound was performed, and checklist had been recorded in all cases including maternal clinical characteristics, ultrasound findings, intraoperative data, maternal and fetal outcomes and postoperative data, and Ultrasound assessment : Routine ultrasound scan was done for evaluation of placental invasion in addition to the standard fetal assessment using 3.5 MHZ abdominal probe (TOSHIBA (Xario) , GE Healthcare), Some patients are stable enough to be evaluated by transvaginal probe 4-7.5 $\mathrm{MHz}$ And using power Doppler, colour Doppler partial bladder filling was considered for evaluating the uterine-serosa interface and the bladder wall.

The following ultrasound criteria of placental invasion were evaluated:

1- Loss of retroplacental clear zone.

2- Retroplacentalmyometrial thickness: smallest myometrial thickness measured between the echogenic serosa and the retroplacental clear space in sagittal plane.

3- Presence of intraplacental lacunar spaces: irregular vascular spaces in the placenta which shows blood flow pattern with color Doppler. Lacunar spaces will be graded according to Finberg and Williams (1992) as follows:

- Grade 0: non-seen.

- Grade 1: 1 to 3 present generally small.

- Grade 2: 4 to 6 present and tend to be larger and more irregular.

- Grade 3: many throughout the placenta and appearing large and bizarre .

4- Bridging vessels between the placenta and bladder wall when using color Doppler.

5- Irregularity and attenuation of the uterinebladder interface.

6- Exophytic mass extending into bladder space .

7- The placental accreta index [4].

\subsection{Statistical analysis}

The greater part information were collected, tabulated Also statistically broke down utilizing SPSS 20. 0 for windows (SPSS inc. , Chicago, IL, usa 2011). Quantitative information were communicated Similarly as those intend \pm sd\& (minimum-maximum), Also qualitative information were communicated as outright frequencies (number) \& relative frequencies (percentage). Nonstop information were checked for typicality by utilizing Shapiro stroll test. Free specimens Student's t-test might have been used to analyze the middle of two Assemblies. Anova (F) test might have been used to analyze the middle of more than two 
gatherings. Percent of unmitigated variables were thought about utilizing Chi-square test. Correlation between two proportions might have been finished utilizing $\mathrm{Z}$ score. Constantly on tests were two agreed. P-value $\leq$ 0 . 05 might have been recognized statistically noteworthy.

\section{Results}

During this study period, total 50 pregnant women who met the inclusion criteria were identified, all were sonographically have placenta previa. and all were suspected radiologically to have placenta Accreta.
All underwent both transabdominal and color Doppler ultrasound, some underwent Both transabdominal \&Transvaginal Ultrasound using Color Doppler antenatally

-10 out of 50 confirmed to be normal Previa.

- Placenta accrete and its variants were confirmed in 40 patients at time of caesarean section

Our study reported that $80 \%$ of the scanned patient were Asymptomatic, the risk of placenta previa accrete doesn't proportionally related to the number of prior cesarean deliveries, Table (1).

Table (1) Frequency distribution of clinical findings among the studied group.

\begin{tabular}{lccc}
\hline characteristic & & No(n=50) & \% $(\mathbf{1 0 0 . 0})$ \\
\hline Previous section & 1 & 14 & 28.0 \\
& 2 & 24 & 48.0 \\
Clinical & 3 & 12 & 24.0 \\
& routine & 40 & 80.0 \\
& bleeding & 6 & 12.0 \\
& pain & 2 & 4.0 \\
& pain and bleeding & 2 & 4.0 \\
\hline
\end{tabular}

Thin myometrium and loss of retroplacental clear space were the highest ultrasound finding at most of the studied cases, Fig (1).

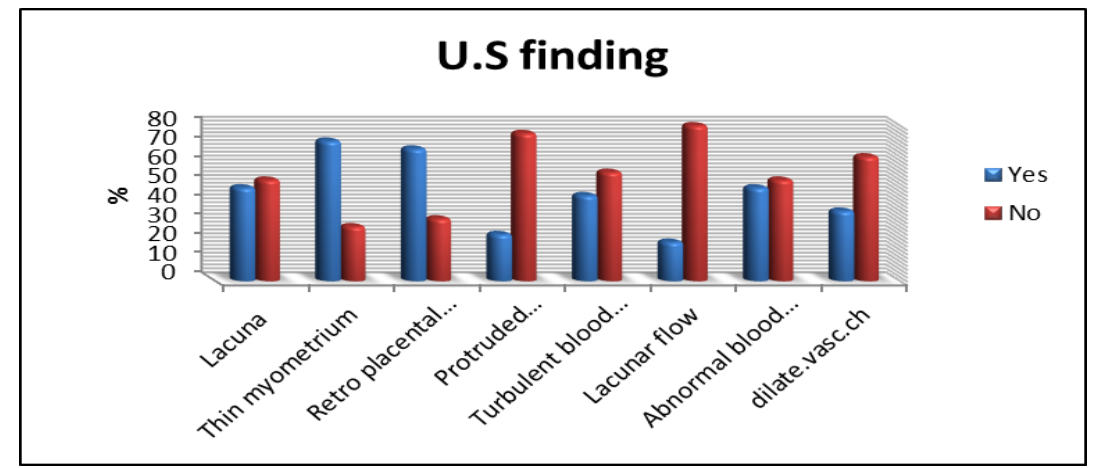

Fig (1) Frequency distribution of US findings among the studied group.

There were statistically highly significant differences with placenta accrete than non adherent placenta in cases with placenta previa in number of pervious CS, it also prove that most of the studied cases were asymptomatic, Table (2).

Table (2) Comparison of placental type according to some clinical aspects.

\begin{tabular}{|c|c|c|c|c|c|c|c|c|c|c|c|}
\hline \multirow{3}{*}{$\begin{array}{l}\text { Placenta } \\
\text { variable }\end{array}$} & & \multicolumn{8}{|c|}{ Placenta $(n=50)$} & \multirow[t]{3}{*}{$\mathbf{X}^{2}$} & \multirow[t]{3}{*}{$\mathbf{P}$} \\
\hline & & \multicolumn{2}{|c|}{ Normal (10) } & \multicolumn{2}{|c|}{ accreta (30) } & \multicolumn{2}{|c|}{ increta $(2)$} & \multicolumn{2}{|c|}{ percreta $(8)$} & & \\
\hline & & No. & $\%$ & No. & $\%$ & No. & $\%$ & No. & $\%$ & & \\
\hline Previous & 1 & 6 & $60.0 \%$ & 6 & $20.0 \%$ & 0 & $0.0 \%$ & 2 & $25.0 \%$ & 13.5 & $0.036^{*}$ \\
\hline \multirow{2}{*}{ section } & 2 & 4 & $40.0 \%$ & 16 & $53.3 \%$ & 0 & $0.0 \%$ & 4 & $50.0 \%$ & & \\
\hline & 3 & 0 & $0.0 \%$ & 8 & $26.7 \%$ & 2 & $100.0 \%$ & 2 & $25.0 \%$ & & \\
\hline \multirow[t]{4}{*}{ Clinical } & Routine & 8 & $80.0 \%$ & 24 & $80.0 \%$ & 2 & $100.0 \%$ & 6 & $75.0 \%$ & 13.7 & .13 \\
\hline & Bleeding & 2 & $20.0 \%$ & 4 & $13.3 \%$ & 0 & $0.0 \%$ & 0 & $0.0 \%$ & & \\
\hline & Pain & 0 & $0.0 \%$ & 2 & $6.7 \%$ & 0 & $0.0 \%$ & 0 & $0.0 \%$ & & \\
\hline & $\begin{array}{l}\text { Pain and } \\
\text { Bleeding }\end{array}$ & 0 & $0.0 \%$ & 0 & $0.0 \%$ & 0 & $0.0 \%$ & 2 & $25.0 \%$ & & \\
\hline
\end{tabular}


Table (3) shows that abnormal placental lacuna, Turbulent blood flow, Lacunar flow and Abnormal blood vessel are highly significant in diagnosis of placenta accrete in cases with placenta Previa but other diagnostic criteria are non-significant.

Table (3) comparison of placental type according to us findings.

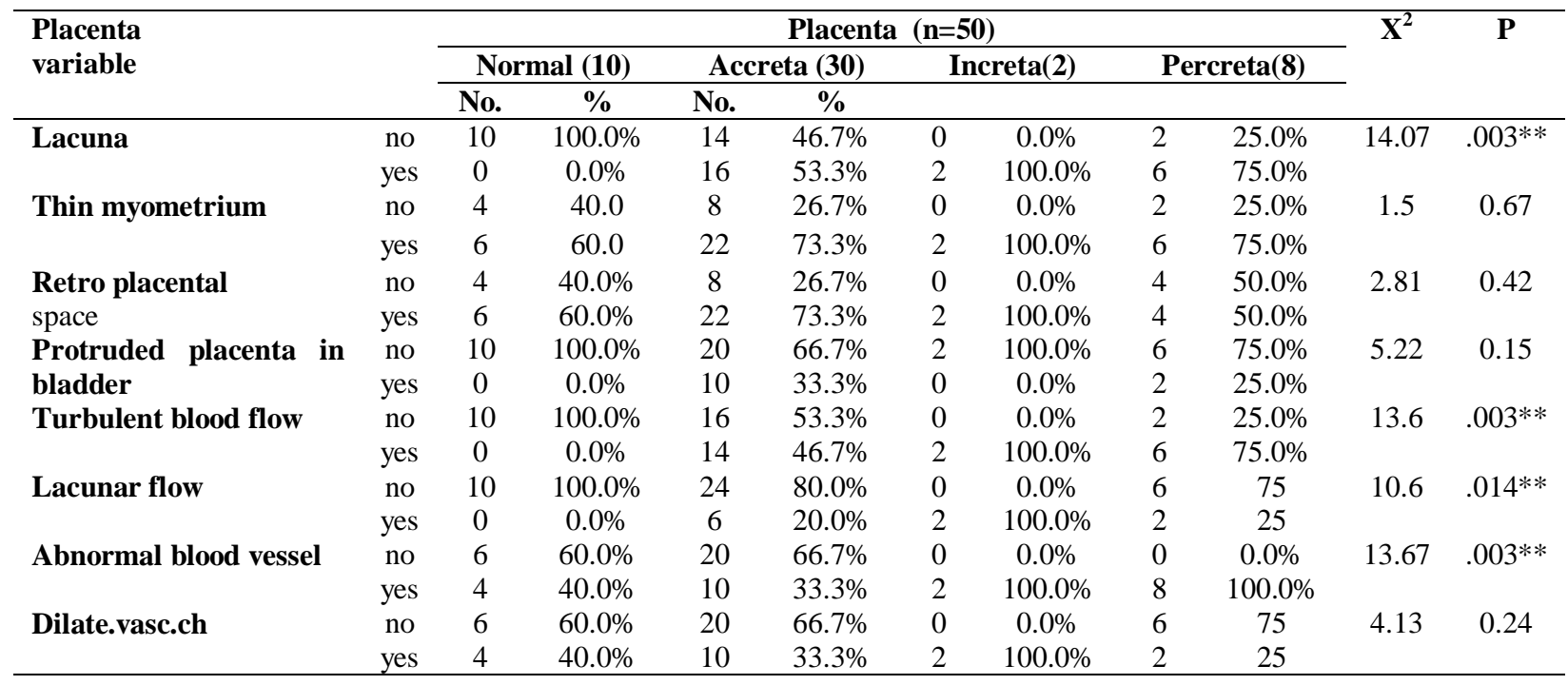

There were no statistically significant differences between degree of adherent placenta in relation to age, gravidity, table (4).

Table (4) comparison of placental type according to age and gestational age.

\begin{tabular}{|c|c|c|c|c|c|}
\hline \multirow{3}{*}{$\begin{array}{l}\text { Placenta } \\
\text { variable }\end{array}$} & \multicolumn{3}{|c|}{ Placenta $(n=50)$} & \multirow{3}{*}{$\begin{array}{l}\text { Anova } \\
\text { (F test) }\end{array}$} & \multirow[t]{3}{*}{$\mathbf{P}$} \\
\hline & Accreta (30) & Increta(2) & $\operatorname{Percreta}(8)$ & & \\
\hline & Mean \pm sd & Mean \pm sd & Mean \pm sd & & \\
\hline Age & $32.47 \pm 3.06$ & $33.00 \pm .00$ & $32.00 \pm 4.47$ & .096 & 0.90 \\
\hline Gestational age & $35.07 \pm 2.79$ & $34.00 \pm .00$ & $33.25 \pm 2.55$ & 1.48 & 0.24 \\
\hline
\end{tabular}

Table (5) shows that abnormal placental lacuna is the highest significant in diagnosis of placenta accrete in cases with placenta previa than the other diagnostic criteria

Table (5) Comparison of placental previa and normal females regarding complications.

\begin{tabular}{|c|c|c|c|c|c|c|}
\hline \multirow[t]{3}{*}{ Placenta } & \multicolumn{4}{|c|}{ Placenta $(n=50)$} & \multirow[t]{3}{*}{$\mathrm{Z}$} & \multirow[t]{3}{*}{$\mathbf{P}$} \\
\hline & \multicolumn{2}{|c|}{ Normal (10) } & \multicolumn{2}{|c|}{ previa (40) } & & \\
\hline & No. & $\%$ & No. & $\%$ & & \\
\hline Lacuna & 0 & $0 \%$ & 24 & $100.0 \%$ & 3.39 & $.000 * *$ \\
\hline Thin myometrium & 6 & 16.7 & 30 & $83.3 \%$ & 0.944 & 0.347 \\
\hline $\begin{array}{l}\text { Retro placental } \\
\text { space }\end{array}$ & 6 & $17.6 \%$ & 28 & $82.4 \%$ & 0.606 & .541 \\
\hline $\begin{array}{l}\text { Protruded placenta in } \\
\text { bladder }\end{array}$ & 0 & $0 \%$ & 12 & $100.0 \%$ & 1.98 & $0.046^{*}$ \\
\hline Turbulent blood flow & 0 & $0 \%$ & 22 & $100.0 \%$ & 3.13 & $.002 * *$ \\
\hline Lacunar flow & 0 & $0 \%$ & 10 & $100.0 \%$ & .176 & 0.076 \\
\hline Abnormal blood vessel & 4 & $16.7 \%$ & 20 & $83.3 \%$ & 5.66 & 0.568 \\
\hline dilate.vasc.ch & 4 & $22.2 \%$ & 14 & $77.8 \%$ & .294 & 0.771 \\
\hline
\end{tabular}




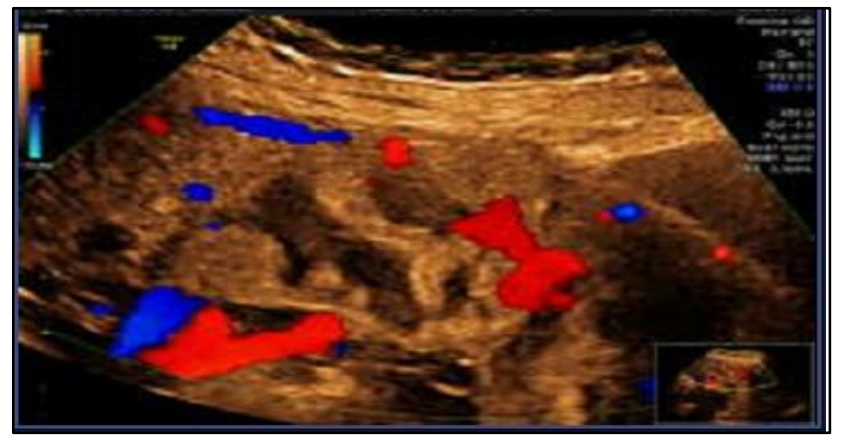

TVUS shows Irregularly shaped placental lacunae with turbulent lacuna flow

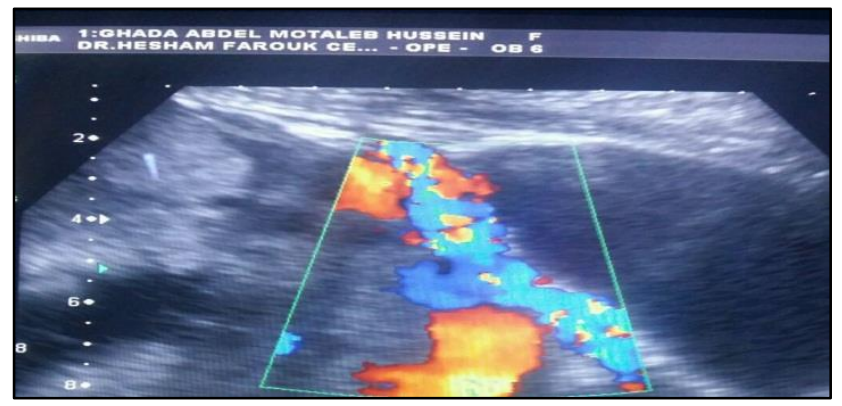

TVUS shows Turbulent blood flow extending from the placenta into surrounding

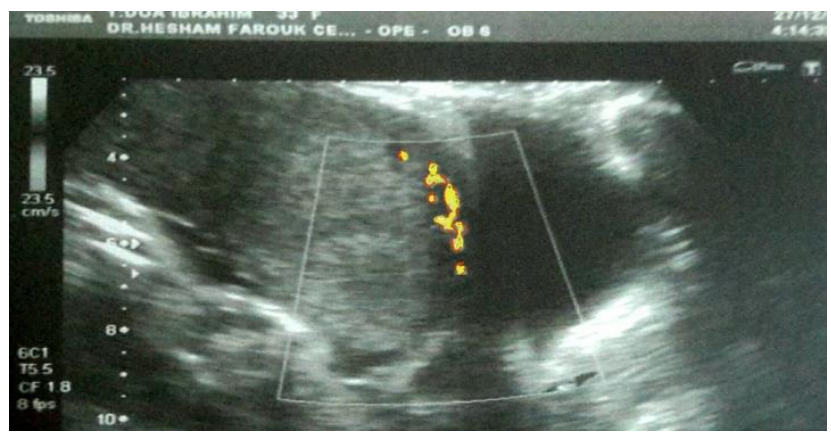

- $\quad$ Thinning of the myometrium overlying the placenta

- Loss of the retoplacental "clear space

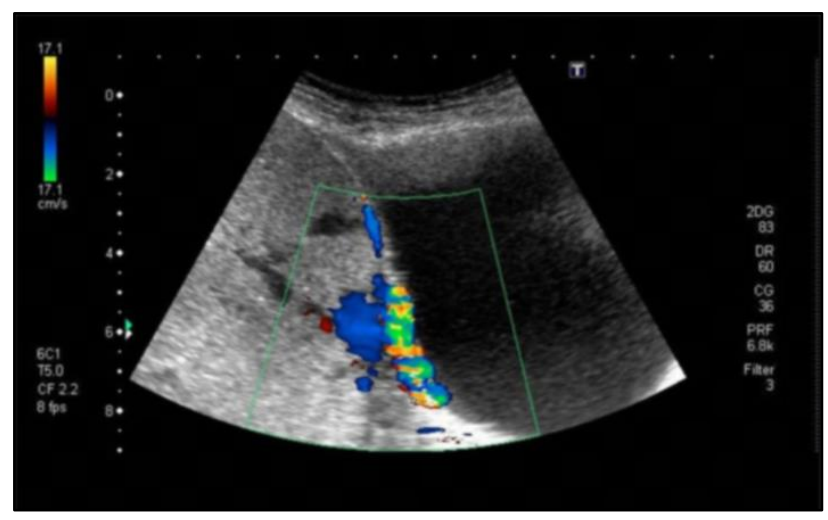

Abdominal U/S shows Interphase hyper vascularity with abnormal blood vessels linking the placenta to the bladder.

\section{Discussion}


Our study news person that those hazard from claiming placenta previa accumulate doesn't identified with the amount for former cesarean conveyances the occurrence rate varies $28 \%$ for those 1 st $-48 \%$ to the second $24 \%$ to 3rd cs. Anyway wing et al [5] accounted for the expanded rate from claiming placenta accumulate $3 \%-11 \%$ - to those In second or more amazing amount about cesarean segments.

This finding ought side of the point concern during those current pattern about cesarean area rate which doesn't make under thought the in length term results of maternal horribleness in rehashed conveyances. This issue might not be considerable in populaces for low conception rate, Anyway it viewed as real for populaces with secondary equality rate [6].

Our contemplate news person that there might have been no statistically huge distinction between follower Also nonadherent placenta clinched alongside connection to the clinical presentation Similarly as $75 \%$ of the patients were alluded Similarly as schedule examination.

Our study news person that there might have been no statistically noteworthy distinction the middle of follower What's more non-adherent placenta clinched alongside connection to age, gravidity What's more equality this steady for cali [7] accounted for that there might have been no statistically huge distinction the middle of map Furthermore non-adherent in connection to age, equality Furthermore gravidity. Be that Jacques et al [8] demonstrated that there might have been Exceedingly critical Contrast the middle of placenta accumulate Furthermore helter skelter gravidity.

A few writers need endeavored with settle on a antenatal finding from claiming placenta accumulate sonographically. Eliza et al. , [9] news person that customary gray- scale ultrasonographic criteria for those analysis of follower placenta might a chance to be advantageous in deciding the patients clinical result and also in get ready her to surgery.

Done our ponder gray scale abdominal alternately basically transvaginal U/S might have been utilized for screening patients and the shade doppler ultrasonic might have been then used to affirm dissection to chosen previapatients. Analysis from claiming placenta accumulate utilizing ash scale relies around particular case or A greater amount of these discoveries. Abnormal placental lacuane, reduction from claiming retro - placenta reasonable space ,Irregular retro - placental sonolucent zone, diminishing or disturbance of the myometrium - bladder interface ,Focal protrusion of the placenta under those divider of the urinary bladder.

This symptomatic criteria steady for Eliza et al. , [9].

To our study the us criteria for finding about placenta accumulate in that request. Diminishing of myometrium, passing of rtroplacental reasonable space, Abnormal placenta Lacauna, taken after Eventually Tom's perusing central exophtic mass, the interface the middle of the uterus and bladder may be spoke to for ash scale sonography as a constant white transport. Its misfortune camwood be moderately clear alternately more subtle, seen best for transvaginal ultrasonography for a incompletely full bladder [7], those PPV of lacunae reveals to additional variety from writer with creator over other indications from claiming cushion.

Likewise, the analysis for placenta accumulate might have been viewed Likewise sure AtAt whatever a standout amongst these shade doppler criteria might have been display. Diffuse lacunar stream design , turbulent blood stream extending from the placenta under encompassing ,Interphase hyper vascularity with abnormal blood vessels linking the placenta of the bladder with helter skelter diastolic blood vessel blood flow, Markedly widened fringe subplacental vascular channels. This reliable with symptomatic criteria for Eliza [9].

Our consider discovered that color doppler required secondary affectability to analysis for placenta accerta for most noteworthy huge criteria is turbilant blood stream extending of the encompassing taken after Eventually Tom's perusing lacunar stream, chou et al discovered that high-flow vessels linking those placenta What's more bladder required a helter skelter affectability and specificity to cushion. However, they warned that mind must be made on hint at that these vessels genuinely associate the placenta and bladder on account of two false positives were the outcome from claiming bladder varices to ladies who needed needed past cesarean areas.

What's more At long last clinicians ought further bolstering make mindful that Tvs for those finding about placenta praevia or a low-lying placenta is better than transabdominalAlso transperineal approaches, and will be safe [10].

\section{Conclusion}

Placenta previa and previous CS were found to be most important risk factors for placenta accreta. Both gray scale and color Doppler ultrasound were very important in 
diagnosing placenta accretaprenatal to reduce maternal \fetal mortality and morbidity but color Doppler is higher sensitivity and specificity.

\section{References}

[1] I. Brosens, R. Pijnenborg, L. Vercruysse, and R. Romero, "The 'Great Obstetrical Syndromes' are associated with disorders of deep placentation," Am. J. Obstet. Gynecol., Vol. 204(3), PP. 193-201, 2011.

[2] J. S. Abramowicz and E. Sheiner, "Ultrasound of the placenta: a systematic approach. Part I: imaging," Placenta, Vol. 29(3), PP. 225-240, 2008.

[3] C. S. Cheung and B. C. Chan, "The sonographic appearance and obstetric management of placenta accreta," Int. J. Womens. Health, Vol. 4(10), p. 587, 2012.

[4] M. W. F. Rac, J. S. Dashe, C. E. Wells, E. Moschos, D. D. McIntire, and D. M. Twickler, "Ultrasound predictors of placental invasion: the Placenta Accreta Index," Am. J. Obstet. Gynecol., Vol. 212(3), PP. 343-e1, 2015.

[5] D. A. Wing, R. H. Paul, and L. K. Millar, "Management of the symptomatic placenta previa: a randomized, controlled trial of inpatient versus outpatient expectant management," Am. J. Obstet. Gynecol., Vol. 175(4), PP. 806-811, 1996.

[6] Y. Gielchinsky, N. Rojansky, S. J. Fasouliotis, and Y. Ezra, "Placenta accreta-summary of 10 years: a survey of 310 cases," Placenta, Vol. 23 (2-3), PP. 210-214, 2002.

[7] G. Calì, L. Giambanco, G. Puccio, and F. Forlani, "Morbidly adherent placenta: evaluation of ultrasound diagnostic criteria and differentiation of placenta accreta from percreta," Ultrasound Obstet. Gynecol., Vol. 41(4), PP. 406-412, 2013.

[8] S. M. Jacques, F. Qureshi, V. S. Trent, and N. C. Ramirez, "Placenta accreta: mild cases diagnosed by placental examination.," Int. J. Gynecol. Pathol. Off. J. Int. Soc. Gynecol. Pathol., Vol. 15(1), PP. 28-33, 1996.

[9] E. M. Berkley and A. Z. Abuhamad, "Prenatal diagnosis of placenta accreta: is sonography all we need?," J. Ultrasound Med., Vol. 32(8), PP. 1345-1350, 2013.

[10]E. Jauniaux, S. Collins, and G. J. Burton, "Placenta accreta spectrum: pathophysiology and evidence-based anatomy for prenatal ultrasound imaging," Am. J. Obstet. Gynecol., Vol. 218(1), PP. 75-87, 2018. 